\title{
CALIBRATION OF RELIABILITY INDEX FOR CRACK WIDTH FOR REINFORCED CONCRETE MEMBERS
}

By

Marina Zakee

B.Eng, Ryerson University, Toronto, 2018

\author{
A major research report \\ presented to Ryerson University \\ in partial fulfillment of the \\ requirements for the degree of \\ Master of Engineering in the \\ program of Civil Engineering
}

Toronto, Ontario, Canada, 2020

(C) Marina Zakee, 2020 


\begin{abstract}
AUTHOR'S DECLARATION
I hereby declare that I am the sole author of this report. This is a true copy of the report, including any required final revisions.

I authorize Ryerson University to lend this report to other institutions or individuals for the purpose of scholarly research.

I further authorize Ryerson University to reproduce this report by photocopying or by other means, in total or in part, at the request of other institutions or individuals for the purpose of scholarly research.
\end{abstract}

I understand that my major research report may be made electronically available to the public. 


\title{
CALIBRATION OF RELIABILITY INDEX FOR CRACK WIDTH FOR REINFORCED CONCRETE MEMBERS
}

\author{
Marina Zakee, Master of Engineering, 2020 \\ Civil Engineering \\ Ryerson University, Toronto, Canada
}

\begin{abstract}
The cracking of Reinforced Concrete (RC) members is a highly random process. However, very few studies are focused on the probabilistic studies of concrete cracking. Second Order Monte Carlo Simulation was applied to determine the reliability index of serviceability limit state for different beam design cases. A proposed equation that has been developed based on a series of experimental work and neural network analysis, to estimate the crack spacing and width in RC members. Model uncertainty was modelled randomly to account for the uncertainties in the chosen crack width model. Monte Carlo subroutine was developed to evaluate the reliability index of the performance function. The results showed that the reliability index for crack width in all generated cases were in the recommended ranges of the acceptable limits that makes the proposed equation adopted in the monitoring strategy at the serviceability limit state as a target limit for monitoring the maximum crack width. The results obtained were compared with previous research work that was performed using First Order Monte Carlo Simulation. The results obtained were similar which indicates that the adopted methodology is reliable. The target limit can be used automatically to make decision for Structural Health Monitoring (SHM) data to repair or inject cracks of RC members. A series of steps were developed to help/guide in the decision-making process, based on the crack width.
\end{abstract}




\section{ACKNOWLEDGEMENTS}

I would first like to thank and express the deepest gratitude to my benevolent supervisor, Dr. Hesham Marzouk, whose generous guidance, encouragement, and persistent help at every stage of my study deserve sincere appreciation. Working under his supervision was a great chance for me to grow professionally and personally.

I also would like to express my gratitude to Dr. Marwa Ahmed for her continuous guidance and support to perform the technical part of my study accurately.

I deeply express my appreciation to former PhD Candidates Dr. Rana Morsy and Dr. Hesham Othman for their previous research work that helped me with my current study.

In addition, I want to extend my appreciation to the examining committee members: Dr. Songnian Li and Dr. Anwar Hossain for their influential insights and feedbacks.

Finally, I would like to heartily thank my parents, my sister and my dearest friend, Fady Freiga, for their endless love and support throughout my entire educational journey. 


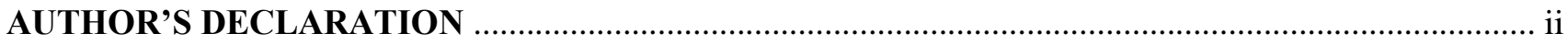

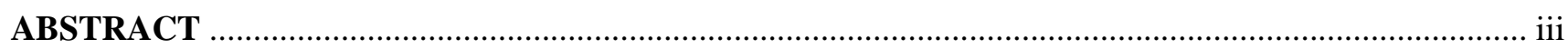

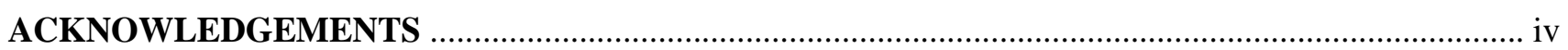

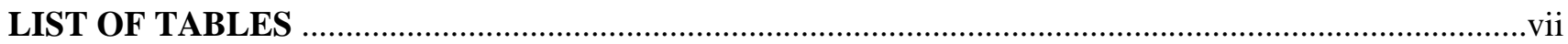

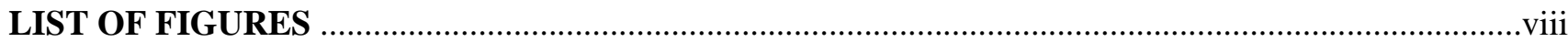

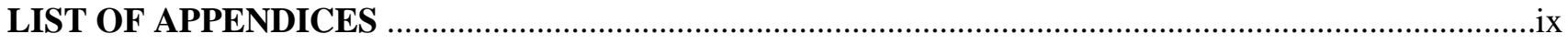

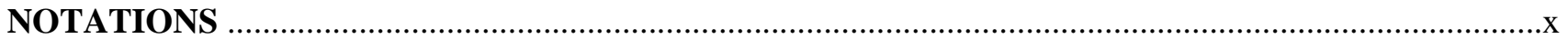

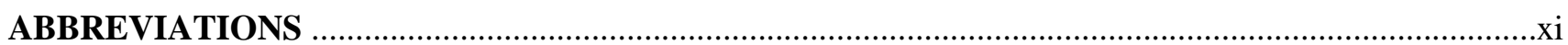

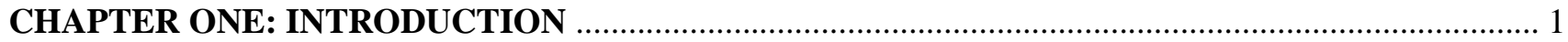

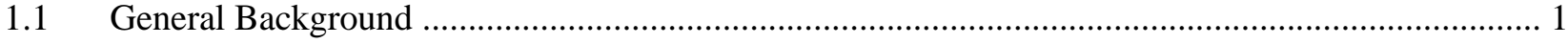

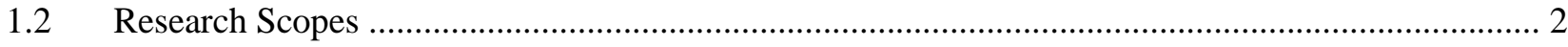

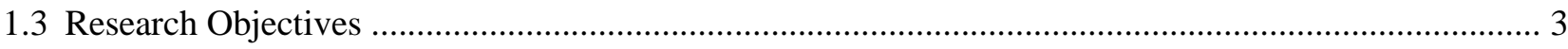

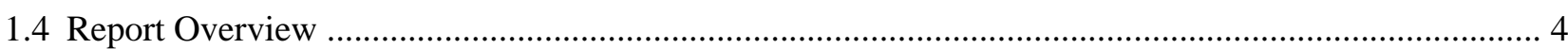

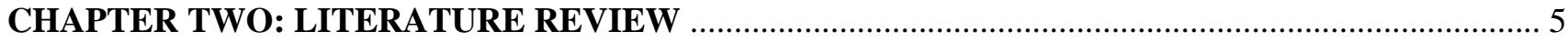

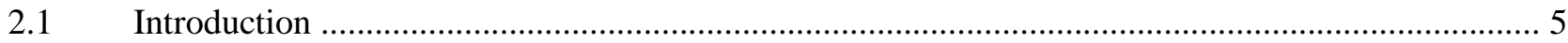

2.2 Cracking of Reinforced Concrete Members ......................................................................... 5

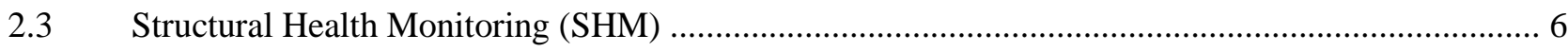

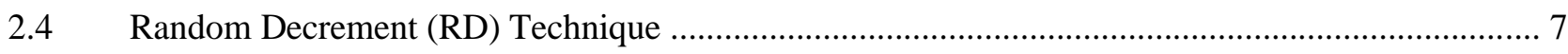

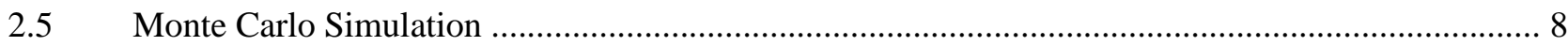

2.5.1 First Order Monte Carlo Simulation.................................................................................. 10

2.5.2 Second Order Monte Carlo Simulation ............................................................................. 11

2.5.3 Monte Carlo Simulation in SHM (reliability index and probability of failure) ....................... 11

2.6 Performance Assessment for Decision-making in SHM .......................................................... 11

\section{CHAPTER THREE: PERFORMANCE LIMILTS FOR MONITORING OF REINFORCED}

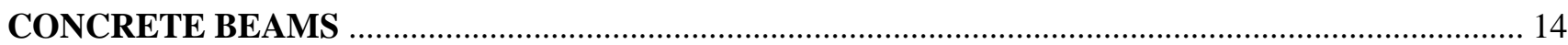

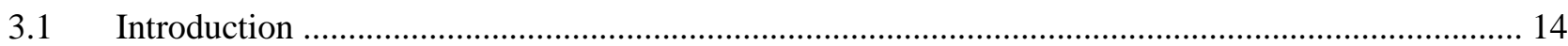

3.2 Reliability Analysis for Crack Width (serviceability limit state) .............................................. 16

3.2.1 Control of Cracking in Concrete Structures .......................................................................... 16

3.2.2 Serviceability Limit Monitoring Using Crack Performance Limit ...................................... 18

3.2.3 Crack Spacing Model and Crack Width Limit ................................................................... 19

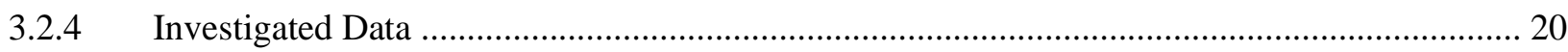

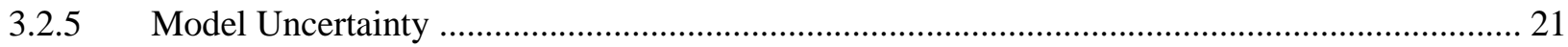

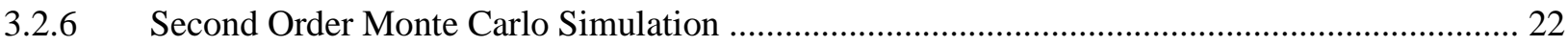

3.3 Ultimate Limit State Monitoring using Decrement Damping Performance Limits ......................... 23 
3.3.1 Decrement Damping Performance Limits ...................................................................... 23

CHAPTER FOUR: RESULTS OBTAINED FROM SIMULATION .......................................... 25

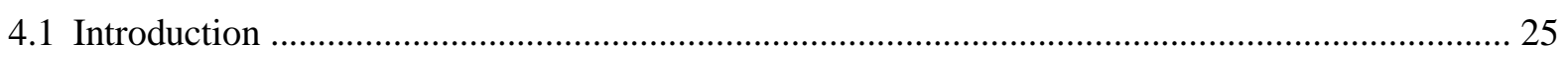

4.2 Results Obtained from Second Order Monte Carlo Simulat......................................................... 26

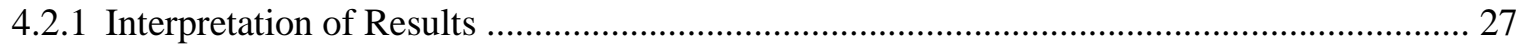

4.2.2 Comparison Between Results from Previous Research Work and Current Find.................. 29

4.3 Decision-Making using the Results Obtained ......................................................................... 30

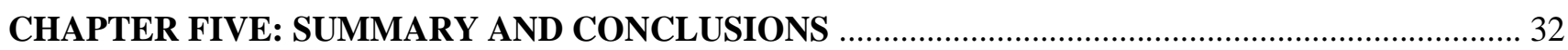

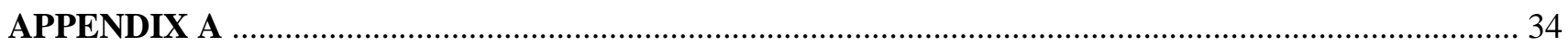

APPENDIX B

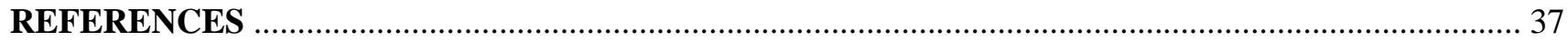




\section{LIST OF TABLES}

Table 1: Beams cases for reliability index study ................................................................ 20

Table 2: Statistical parameters for the decision variables .................................................... 20

Table 3: Probability of failure and corresponding reliability index value .................................. 23

Table 4: Decrement damping ratio reliability index for different performance limits ................... 24

Table 5: Results of reliability index for all studied cases .................................................. 25

Table 6: Reliability index values of previous research work ............................................ 28

Table 7: Comparison between previous and current research work ......................................... 29

Table 8: Suggested action depending on the crack width ................................................ 31 


\section{LIST OF FIGURES}

Figure 1: Common Probability Distributions ....................................................................... 9

Figure 2: Probabilistic performance for safety evaluation ............................................... 15

Figure 3: Schematic drawing for crack spacing prediction formulation ................................... 17

Figure 4: Steps used for Second Order Monte Carlo Simulation ............................................. 22

Figure 5: Proposed reliability index for the decrement damping values .................................... 24

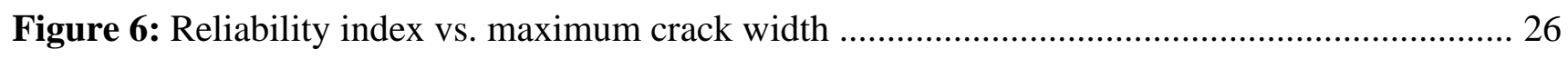

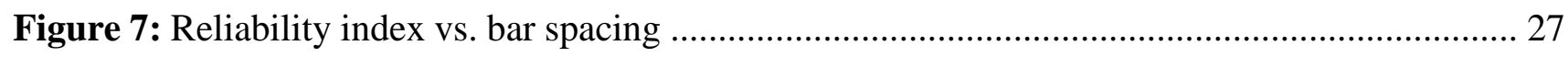

Figure 8: Diagnostic approach for performance limits of concrete structures .............................. 30 


\section{LIST OF APPENDICES}

Appendix A: List of 60 data sets collected from experimental studies.....................34

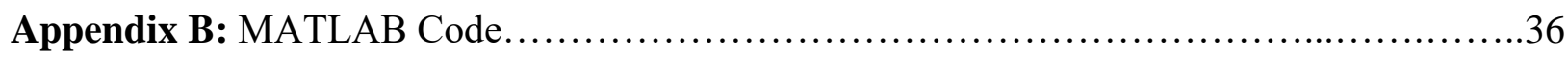




\section{NOTATIONS}

$\begin{array}{ll}\mathrm{S}_{\mathrm{avg}} & \text { Average crack spacing } \\ \mathrm{W}_{\mathrm{avg}} & \text { Average crack width } \\ \mathrm{W}_{\max } & \text { Maximum crack width } \\ \mathrm{W}_{\text {lim }} / \mathrm{W}_{\text {exp }} & \text { Maximum allowable crack width } \\ \varepsilon_{\mathrm{s}} & \text { Average strain of steel } \\ f_{y} & \text { Yield stress of steel } \\ \mathrm{d}_{\mathrm{b}} & \text { Reinforcement bar diameter } \\ \mathrm{S}_{\mathrm{b}} & \text { Reinforcement bar spacing } \\ \mathrm{C}_{\mathrm{c}} & \text { Concrete Cover } \\ \mathrm{G} & \text { Performance function } \\ \mathrm{R} & \text { Resistance } \\ \mathrm{S} & \text { Load effects } \\ \mathrm{P}_{\mathrm{f}} & \text { Probability of failure } \\ \beta & \text { Reliability index } \\ \Phi & \text { Standard normal cumulative distribution function } \\ \mathrm{C} & \text { Model uncertainty }\end{array}$




\section{ABBREVIATIONS}

SHM Structural Health Monitoring

NDT Non-Destructive Testing

RD Random Decrement Damping

DD Decrement Damping

PPP Probability Paper Plot 


\section{CHAPTER ONE: INTRODUCTION}

\subsection{General Background}

The cracking of Reinforced Concrete (RC) members is a highly random phenomenon. It is controlled by many factors for example, concrete cover thickness, reinforcing bar diameter, concrete compressive strength etc. Therefore, concrete structures should be continuously monitored to ensure that the structure remains in an acceptable state. This process is called Structural Health Monitoring (SHM). SHM occurs periodically to identify the damage level and the structure performance. This step is crucial in decision making process. In other words, a decision of whether to fix the bridge (resurfacing), rehabilitate it or demolish it depends on the structural performance data obtained during the SHM process. Most structural defects are related to serviceability conditions rather than strength. One of the main serviceability conditions of concrete is the crack width. The crack width is usually controlled by the cracking limit state of the Code. The serviceability limit state (SLS) provides a maximum crack width limit. If the structure's crack width exceeds the limit of the Code, a decision has to be taken, whether to inject the crack or re-surface the structure. The reliability index of crack limit can be investigated using Monte Carlo Simulation. In addition, the probability of failure can also be obtained using Monte Carlo Simulation. In the simulation, all the factors that affect the crack propagation in the proposed crack width function were considered as random variables. These variables include reinforcement spacing, bar diameter, concrete cover and concrete compressive strength. The reliability index and probability of failure can be used by the decisionmaker to decide whether to re-surface the bridge or demolish it, by comparing the reliability index and probability of failure values to the target ones. 


\subsection{Research Scopes}

Performance assessment of a RC member can be performed using different methods, for example, Non-Destructive Testing (NDT), visual inspection, etc. However, the scope of this research is to find a reliable and statistical method to know about the condition of a $\mathrm{RC}$ member. In other words, calibrate the reliability index for the crack width model chosen. This was achieved by testing a crack width model with different random variables using Second Order Monte Carlo Simulation. The First order Monte Carlo Simulation was carried out in previous research work (Othman, Morsy, \& Marzouk, 2014) to determine the reliability index for serviceability limit state. The variables that contribute to the performance of concrete of 60 different beams were obtained. Then, a performance function was developed to compare the crack width values obtained with the limit of crack width stated in the Canadian Code (CSA A23.3-M94, 2014). The reliability index and probability of failure of the crack width model were also obtained and compared with the acceptable target values. These values were then used to develop a decision-making tool to help the decision-maker to decide about the condition of a RC member. By using this method, the decision taken will be carried out based on a reliable statistical decision (objective) rather than a subjective decision.

The significance of this research is to provide a statistical approach to determine/calibrate the reliability index of any $\mathrm{RC}$ member using any crack width performance function. This is to be done using Second Order Monte Carlo Simulation, where the decision variables of the chosen performance function are modelled as random statistical variables with their corresponding probability distribution. This helps the decision-maker to make a statistical decision based on the values of reliability index obtained from Second Order Monte Carlo Simulation. 


\subsection{Research Objectives}

The objective of this research is to calibrate the reliability index of the proposed crack width model to help obtain a reliable decision regarding the condition of a $\mathrm{RC}$ member;

1. To model the crack width function proposed using Second Order Monte Carlo Simulation, where all the factors that affect crack propagation were considered as random variables.

2. To investigate the reliability of the serviceability limit state of RC members and compare it with the crack width limit stated in the Canadian Code (CSA A23.3-M94, 2014).

3. To develop a decision-making procedure/tool to help the decision maker to decide whether to resurface the bridge, inject the cracks or rehabilitate it etc.

\subsection{Report Overview}

Chapter 1 presents the introduction including general background, research scope and research objectives.

Chapter 2 describes the literature review of the project including the basic concepts about cracking of concrete and the main causes of it. Also, it describes the general concept of SHM and its importance. In addition, the Random Decrement (RD) technique will be discussed because the experimental crack width data of the experimented beams was obtained using RD technique and the performance limits used will be according to the change in the Decrement Damping (DD) limits. Furthermore, the concept of Monte Carlo Simulation will be discussed; First order and Second order, the main differences between them and the reason behind doing Second order Monte Carlo Simulation. Finally, the performance assessment decision-making process will be addressed. Chapter 3 describes the reliability analysis for crack width using the serviceability limit state. In addition, the control of cracking in concrete, serviceability limit monitoring using performance limit, crack spacing, and crack width models and model uncertainty will be explained. Moreover, the 
procedure for Second order Monte Carlo based on DD performance limits will be presented and how they relate to the results obtained.

Chapter 4 demonstrates the results obtained from the Second order simulation and if they are within the acceptable limits.

Chapter 5 presents the summary and conclusions of the research. 


\subsection{Introduction}

\section{CHAPTER TWO: LITERATURE REVIEW}

The aim of the present chapter is to provide a conceptual background and to discuss related theoretical and empirical studies for Structural Health Monitoring (SHM) of Reinforced Concrete (RC) members. Primarily, the causes of cracking of RC members and how it occurs will be presented. Then, the general concept of SHM including definition, history, development and advantages of SHM will be described. In addition, the brief concept of Random Decrement (RD) Technique will be explained because the experimental crack width data used in this study were obtained using RD technique. Furthermore, a detailed explanation of the Monte Carlo Simulation concept will be described along with the main differences between First Order and Second Order Monte Carlo Simulation. Finally, the assessment of RC members based on the performance, and how can the performance assessment help with decision making will be discussed.

\subsection{Cracking of Reinforced Concrete Members}

Cracking of concrete is a highly random process. It can happen as a result of many factors and at any stage of the concrete structure life. Cracking is usually the first sign of distress in concrete. Cracking can occur in both hardened and fresh, or plastic, concrete as a result of volume changes and repeated loading. This involves tensile stresses being loaded onto the concrete, the cracks occurring when the force exceeds its maximum tensile strength. It is important to understand the reasons why cracking occurs, the type of crack formed, and cracks' effects on structural stability. Once the reason is figured out, the appropriate action can be taken. This may mean leaving the crack alone, injecting the crack with an appropriate material, or applying other suitable repair methods. It is important to identify the primary concern in regard to any cracking. The main concerns are whether the cracks are affecting structural integrity as a result of reduced durability. (Giatec, 2019) 


\subsection{Structural Health Monitoring (SHM)}

Civil structures should be efficiently designed such that, catastrophic failures have to be avoided. This has been achieved by considering safety factors in order to compensate for potential lack of knowledge on the structure's behavior, and to create a margin between the real-time operational loading and the remaining residual strength of structure's material to resist the applied load.

Reduction in the structure's strength is attributed to degradation and damage induced by the operational loading and environmental conditions over its service life. Once more knowledge about the structure's behavior is gained, safety factors may be reduced without compromising the likelihood of failure. This knowledge of the performance of the structure at a given time, in turn, has a great importance due to its impact on avoiding catastrophic failures, along with economic benefits. Increasing the impact of economic considerations leads to a development of new design of health monitoring for structures.

During the inspection of a structure, its performance is investigated by monitoring the magnitude and location for any damage, especially in vulnerable or critical members.

These monitoring systems rely on scheduled inspections intervals and maintenance plans. This adds cost and confines economic profits. The main purpose of the monitoring systems is to provide a continuous assessment of the structure's performance.

The development and practical implementation of accurate and efficient SHM methods involves a number of issues. The efficiency of the SHM strategies depends on observation, diagnosis, and action as well as the sensor measurements and locations, identification methods for detection of damage and deterioration, and finally decision-making for the structural safety.

SHM is based on the data collected that reflects the changes in response behavior of the structure due to applied loads. These data are collected mainly through sensor networks, interrogation system 
measurements, and visual investigation. These sensors are used to measure features sensitive to damage in the structure that affects the integrity of the structure's performance.

These data, such as cracking, strain, and stresses, can provide a health assessment of the structure; based on these properties. The structure's performance can be evaluated accurately through detecting the occurrence of damage. The damage detection results support the identification of the current structural condition and estimation of the remaining life of the monitored structure. Different damage detection techniques are used for both local and global damage monitoring of structures. Local monitoring is the process of observation of a local phenomenon such as strain or cracking to evaluate the severity of the damage; however, it is not considered efficient for long-term health monitoring systems, as the condition of the structure cannot be determined on a local level. Global monitoring of structures involves observing the dynamic parameters such as the natural frequency, damping ratio, and mode shapes, which are capable of reflecting the global performance of the structure.

\subsection{Random Decrement (RD) Technique}

The Random Decrement (RD) technique is based on the identification of output measurements and is considered as an effective diagnostic technique for damage detection. The RD technique is based on the detection of changes in dynamic properties calculated from the measured response. It has been illustrated that there is a unique randomdec signature for every damage size, and those signatures are compared to a baseline data obtained from the structure in its healthy state. The change in the signature from the baseline randomdec signature is could be used to indicate the damage extent in the structure. The main advantage of the RD technique is that it can be used to determine the structure-free vibration response from stationary response measurements without prior knowledge of excitation forces. Implementation of the RD technique in vibration-based SHM provides an accurate approach for identifying the dynamic parameters. (Ismail et al., 2006) 


\subsection{Monte Carlo Simulation}

Monte Carlo simulations are used to model the probability of different outcomes in a process that cannot easily be predicted due to the intervention of random variables. It is a technique used to understand the impact of risk and uncertainty in prediction and forecasting models. Monte Carlo simulation is also referred to as multiple probability simulation. The number of simulations is usually around 100,000 iterations, to compensate for the uncertainty of the random variables used. Monte Carlo simulation performs risk analysis by building models of possible results by substituting a range of values - a probability distribution - for any factor that has inherent uncertainty (Investopedia, 2019). It then calculates results over and over, each time using a different set of random values from the probability functions. Depending upon the number of uncertainties and the ranges specified for them, a Monte Carlo simulation could involve thousands or tens of thousands of recalculations before it is complete. Monte Carlo simulation produces distributions of possible outcome values. By using probability distributions, variables can have different probabilities of different outcomes occurring. Probability distributions are a much more realistic way of describing uncertainty in variables of a risk analysis. The common probability distributions are shown in Figure 1. (Palisade, 2019)

Common probability distributions include:

\section{Normal}

Or "bell curve." The user simply defines the mean or expected value and a standard deviation to describe the variation about the mean. Values in the middle near the mean are most likely to occur. It is symmetric and describes many natural phenomena.

\section{Lognormal}

Values are positively skewed, not symmetric like a normal distribution. It is used to represent values that do not go below zero but have unlimited positive potential. 


\section{Uniform}

All values have an equal chance of occurring, and the user simply defines the minimum and maximum.

\section{Triangular}

The user defines the minimum, most likely, and maximum values. Values around the most likely are more likely to occur.

\section{PERT}

The user defines the minimum, most likely, and maximum values, just like the triangular distribution. Values around the most likely are more likely to occur. However, values between the most likely and extremes are more likely to occur than the triangular; that is, the extremes are not as emphasized.

\section{Discrete}

The user defines specific values that may occur and the likelihood of each. (Palisade, 2019)

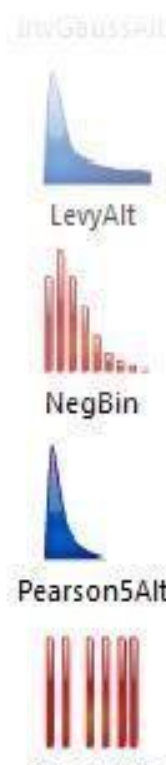

Resample

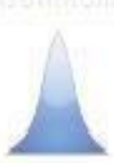

Logistic

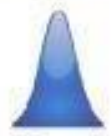

Normal
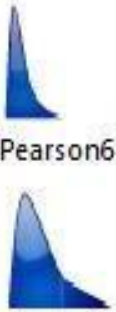

Splice

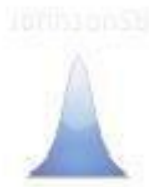

LogisticAlt

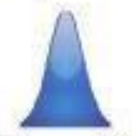

NormalAit

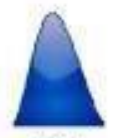

Pert

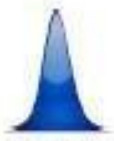

Student

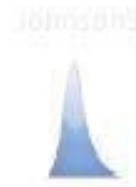

LogLogistic

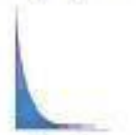

Pareto

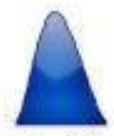

PertAlt

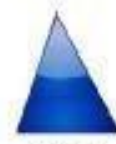

Triang

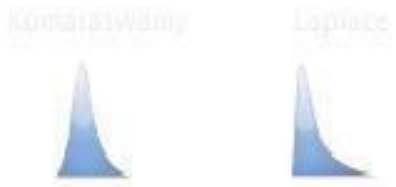

LogLogisticAlt

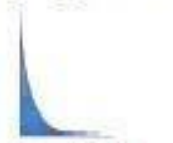

ParetoAlt
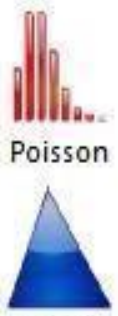

TriangAlt
Lognorm

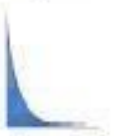

Pareto2

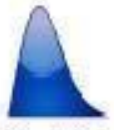

Rayleigh

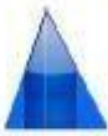

Trigen

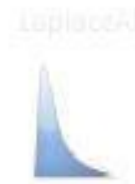

LognormAlt

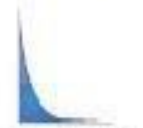

Pareto2Alt

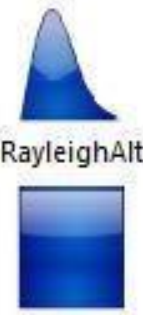

Uniform

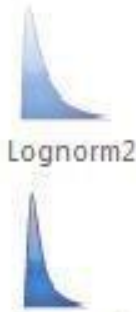

Pearson5

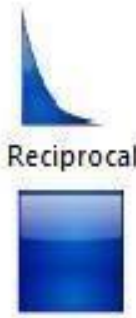

UniformAlt

Figure 1: Common Probability Distributions

During a Monte Carlo simulation, values are sampled at random from the input probability distributions. Each set of samples is called an iteration, and the resulting outcome from that sample 
is recorded. Monte Carlo simulation does this hundreds' or thousands of times, and the result is a probability distribution of possible outcomes. In this way, Monte Carlo simulation provides a much more comprehensive view of what may happen.

\subsubsection{First Order Monte Carlo Simulation}

First order Monte Carlo Simulation is used to determine the model uncertainty/process variability based on a performance function. Many softwares can be used for example TreeAge and Microsoft Excel. The general technique is running a large number of simulations (100,000 or more) using random variables, which represent the decision variables, to determine the probability of failure of the model; performance function. In other words, the decision variables of a performance functions are simulated as random variables using a probability distribution function of a known mean and standard deviation. The probability distribution of the outcome is determined based on many deterministic values.

\subsubsection{Second Order Monte Carlo Simulation}

Second order Monte Carlo Simulation is used to determine parameter uncertainty. In this simulation, the probability distribution of the outcome is generated based on randomly distributed (random probability distribution) values rather than deterministic values. The randomly distributed values were generated according to the number of simulations used (10,000 or 100, 000 etc.). Using Second Order Monte Carlo simulation results in more accurate result because the uncertainty in each variable was taken into consideration. In other words, it provides more reliable results for risk analysis.

\subsubsection{Monte Carlo Simulation in SHM (reliability index and probability of failure)}

The outcomes of Monte Carlo Simulation are probability of failure $\left(\mathrm{P}_{\mathrm{f}}\right)$ and reliability index $(\beta)$. The probability of failure is defined as the probability for exceeding a limit state within a defined reference time period. When this occurs an unintentional condition of a considered building component is reached. The reliability index is a measure of how reliable a certain performance 
function according to the value of the decision variables. More details about the probability of failure and reliability index will be presented in Chapter 3. (Müller, 2010)

\subsection{Performance Assessment for Decision-making in SHM}

The performance assessment analysis is required for establishing an analytical model representing the structure's lifetime performance using probabilistic methods to solve uncertainties occurrence. The performance assessment of structures is usually applied after the observation and evaluation of damage for monitoring the structural performance and for developing new strategies for maintenance, inspection, and assessment in order to analyze the optimal option. This performance assessment includes the evaluation of the structure's life cycle which can show better alternatives that help with the decision-making, such as minimizing the number of inspections and optimizing the number of structures that require immediate repair, rehabilitation, or replacement. For the life cycle analysis, a model of deterioration is created; probabilistic models are developed to deal with the uncertainties to integrate data into assessment for the lower and upper bounds of life expectancy and the estimation of the lifetime range. Various random impact factors such as changes in loading and environmental conditions could initiate time dependent deterioration in civil infrastructure, especially concrete bridge structures that are exposed to harsh environment conditions, which is prone to rapid deterioration. Influencing factors may range from freeze thaw cycling, traffic wear and tear, exposure to aggressive environments such as sulphate, chloride ions, construction or design errors and inadequate maintenance regimes (Morcous, 2006).

(Robelin and Madanat, 2007) formulated a realistic model of bridge deck deterioration using Markov chain model for developing new strategies for maintenance plan. There are many Markovian deterioration approaches for the management and sustainability of the infrastructures, such as using assessment-based method using either discrete or continuous Markov chain is being used for deterioration modeling, and the deterministic approach of condition data and fixed deterioration 
curve. Markov chain is a finite state probability model in order to describe a certain type of stochastic process that moves in sequence phases through discrete points in time according to fixed probabilities. Markov decision process is based on the concept of defining states of facility conditions and obtaining the probabilities of facility condition transition from one state to another during one inspection period (Jiang et al., 1988). The Markov chain approach is suitable from the visual inspection data but not convenient for estimation of the reliability of the structure strength (Frangopol, 2001). A reliability-based approach will be achieved for the structure deteriorating prediction. This approach is more rational to state the structure condition. As the reliability index is considered as a good measure of the safety of the structure.

Performing a condition assessment to monitor structural integrity is essential for decision making regarding maintenance plans for aging structures. There are difficulties in conducting a condition assessment tool related to handling the uncertainties in the measurement, such as the construction material and the magnitude of the applied forces.

Structural reliability for performance assessment supplies a framework to identify uncertainties in strength and demand and to evaluate the probability of failure. It is developed by combining probability, statistics, and random processes with the principles of the structural mechanics of parameters to form the basis of modern structural design, and assessment codes are developed and calibrated. Analyzing the cracking limit of structures at the serviceability limit state using reliability methods has been recognized to be more rational than deterministic methods; so many researchers have been attracted to cracking limit state reliability analysis. (Quan and Gengwei, 2002) discussed the calibration of the reliability index of reinforced concrete beams for the serviceability limit state of the maximum crack width equation of the Chinese code. The First Order Monte Carlo Simulation was applied to determine the reliability index. (Honfi et al., 2012) investigated the reliability of flexural beams for serviceability. 
Another reliability study was carried out by (He and Qiu, 2008) to assess the maximum crack width of FRP reinforced concrete beams, concluding the value of the average reliability index. A probabilistic study was performed by (Kwon et al., 2009) based on field investigation to predict the service life with early age cracking in reinforced concrete structures exposed to a marine environment, and the calculated probabilities of failure using Monte-Carlo simulations were equal to 7 and $10 \%$.

Another approach has been proposed by (He et al., 2011) to evaluate the bridge performance based on measured strain data; it was mentioned that for most structural members, the acceptable limit of the reliability index is equal to 3.5 for a reliability condition assessment tool based on inspection and design data is used to derive a target reliability index in serviceability design, and prediction of the remaining lifetime of concrete bridges at the serviceability limit state based on cracks on concrete and the element deflection limits.

Therefore, the current research provides a new method/approach to calibrate the reliability index for the chosen performance function, using a statistical approach rather than a subjective rating approach. The chosen research method combines several methods in order to make a statistical condition for a reinforced concrete member based on the crack width. 


\section{CHAPTER THREE: PERFORMANCE LIMILTS FOR MONITORING OF REINFORCED \\ CONCRETE BEAMS}

The present chapter describes the suggested different levels, serviceability and ultimate limit state, of structural reliability methods for health monitoring of concrete beams, and a proposed performance limits used for assessment of the beams' integrity, in order to analyze the optimal maintenance option using Second Order Monte Carlo Simulation. It also outlines the crack width limit, performance limit and model uncertainty equations that were used in the previous research work, where results were obtained using First Order Monte Carlo Simulation. These equations and limits will be used further in this research to obtain the results using the Second Order Monte Carlo Simulation.

\subsection{Introduction}

SHM is a periodic observation of the structure performance and identification of damage level, in order to evaluate the maintenance requirements for the current state of the structure. Performing a condition assessment to evaluate its integrity, is essential for decision-making of ageing structures' maintenance plans. There are difficulties in conducting a condition assessment related to handling of the uncertainties in the measurement such as construction material and magnitude of the applied forces. A reliability performance assessment is a tool based on inspection and design data that is used to derive a target reliability index for remaining lifetime prediction. (Müller, 2010) Limit state design, is a design approach to check the design safety against failure occurrence at different limit states and to determine the modes of failure. For reinforced concrete structures, there are five design limits; durability, fire resistance, serviceability limit state, ultimate limit state and special limit state. The limit state function $(\mathrm{G})$ is defined as the difference between the loading and the resistance of the structure. The maximum resistance of the structure should be greater than the applied loads with a reasonable margin to ensure the safety of the design and due to the variability in resistance and 
loading, the probability-based design is used to define the probability that the structure will satisfy the safety and performance requirements. The structural performance function is defined by a limit state function and it is expressed as (Ellingwood,2003);

$G(x)=0$

where $\mathrm{x}$ is the vector difference between resistance and load random variables (a random variable is a defined number associated to a given event that is unknown before the event occurs). The resistance of the structure (R), should be higher than the load $(\mathrm{S})$. The safety of a structural component depends on its resistance $\mathrm{R}$ and load effects $\mathrm{S}$ that could be expressed in the limit state function. The limit state function $(G)$ is evaluated as if $G<0$ means that the structure element is unsafe, and if $G \geq 0$ means that it is safe and if $\mathrm{G}=$ zero is called the limit state. Figure 2 shows the probabilistic performance for safety evaluation. The probabilistic performance for safety evaluation is based on the limit state function as shown below;

$G=R-S$

Therefore, the probability of failure $\left(\mathrm{P}_{\mathrm{f}}\right)$ can be written as

$P_{f}=P(R-S<0)$

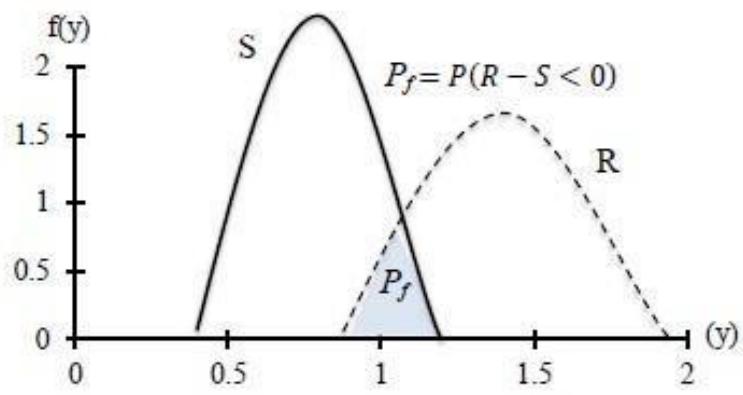

Figure 2: Probabilistic performance for safety evaluation

Since the structural performance function is based on the large number of random variables, it is more convenient to measure the safety of the structural in terms of the reliability index $(\beta)$. The equation of the probability of failure in terms of the reliability index $(\beta)$ is; 
$P_{f}=\Phi(-\beta)$

Where, $\Phi$ is the distribution function of the standardized normal distribution.

\subsection{Reliability Analysis for Crack Width (serviceability limit state)}

The serviceability limit states are the limits that represent unsatisfactory of the functional behavior of the structure including excessive deflection, excessive crack widths and excessive vibrations. Excessive deflection is visually unaccepted; however, its position is well determined and could be measured using linear variable displacement transformer (LVDT) or laser deflection scanning sensor. Excessive cracking could be unsightly and causes leakage that leads to corrosion of reinforcement and a deterioration of the concrete. Therefore, it is important to focus on the design crack width limit of concrete elements. In the current study, a reliability-based analysis is implemented for the calibration of reliability levels on crack width.

\subsubsection{Control of Cracking in Concrete Structures}

Cracking control is essential for the serviceability limit state in concrete structural design especially for structures such as bridges, high-rise buildings, offshore platforms, and containment structures for nuclear power plants. The cracking of reinforced concrete beams is a highly random phenomenon that occurs due to low tensile strength and lack of ductility. Monitoring the crack pattern is important for assessing the overall health of a structure and determining the required repair and maintenance plan. Cracking of concrete structures has been the main focus of researchers for decades; they have been conducting investigations on cracking in concrete to develop a formula to calculate the crack width. The most significant parameters that have been widely agreed to control cracking are the reinforcing steel stress, concrete cover, bar spacing, and the area of concrete surrounding each bar (Dawood and Marzouk, 2011). Figure 3 shows the schematic drawing for crack spacing prediction formulation. 


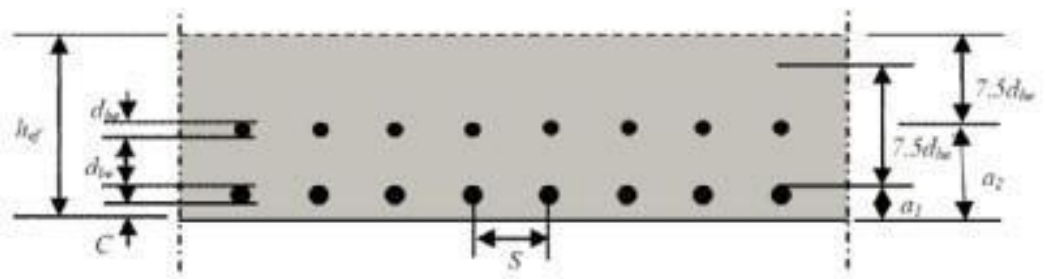

Figure 3: Schematic drawing for crack spacing prediction formulation

The following two proposed equations by (Dawood and Marzouk, 2011), for crack width predictions obtained using multi-variable regression analysis of experimental data. Based on this statistical investigation, different equations were proposed to estimate the value of the average crack width at the serviceability stress limit state thick plates. The first equation is proposed to estimate the value of the crack width for beams and one-way slabs;

$W_{m}=0.0134 f_{c}^{-0.97} d_{b}^{0.43} S_{b} 1.02$

where, $\mathrm{W}_{\mathrm{m}}$ is the crack width; $\mathrm{f}_{\mathrm{c}}$ is the concrete compressive strength; $\mathrm{d}_{\mathrm{b}}$ is the rebar diameter; and $\mathrm{S}_{\mathrm{b}}$ is the bar spacing. The second equation is proposed to estimate the value of the crack width for two-way slabs;

$W_{m}=0.95 f_{c}^{0.04} d_{b^{0.83}} S_{b^{0.04}} C_{c^{1.10}} h^{-1.43}$

Where, $W_{c r}$ is the crack width; $f_{c}$ is the concrete compressive strength; $d_{b}$ is the rebar diameter; $C_{c}$ is the concrete cover; $\mathrm{S}_{\mathrm{b}}$ is the bar spacing and $\mathrm{h}$ is the slab thickness.

\subsubsection{Serviceability Limit Monitoring Using Crack Performance Limit}

Reliability analysis of serviceability limit state for reinforced concrete beams; in particular, reliability based on the crack width used for calibration of the reliability levels. A reliability analysis was used for the crack width to determine the reliability index, for checking the accuracy of any proposed model to predict the maximum crack width which was formulated by curve-fitting of experiments tests to establish a crack width limit for monitoring concrete structure. The limit state reliability approach was applied for the crack width reliability calculations, considering it as the function of 
random variables such as the concrete cover, reinforcing spacing and bar diameter. A structural deterioration reliability model was performed to get the probability of failure. The limit state function that can be expressed in the performance function $(\mathrm{G})$ as the difference between the random resistances of the member, and the random load effect acting on the member;

$G=R-S=W_{\exp }-C . W_{\max }$

where, $\mathrm{W}_{\exp }$ is the crack width, it is a deterministic value. $\mathrm{W}_{\max }$ is the maximum crack width calculated using crack width equation and $\mathrm{C}$ is the model uncertainty factor of the evaluation of maximum crack width. Using a crack control parameter, (CSA A23.3-M94, 2014) limits the maximum crack width to be 0.40 and $0.33 \mathrm{~mm}$ respectively for exterior and interior exposure. (ACI $318-99,2019)$ also limits crack widths to $0.40 \mathrm{~mm}$ for all exposure conditions. Developing the performance functions for reinforced concrete members requires a wide range of realistic parameters in the design space. If the performance function $(G>0)$ the structure is safe, otherwise it considered to be unsafe. The probability of failure $\left(\mathrm{P}_{\mathrm{f}}\right)$ is equal to;

$P_{f}=P(R-S<0)$

As mentioned previously, structural safety is measured in terms of the reliability index $(\beta)$. MonteCarlo simulation is used to evaluate the solution for the random variable and to calculate the probability of failure.

\subsubsection{Crack Spacing Model and Crack Width Limit}

The investigated crack spacing model proposed by (Elshafey et al., 2013) at Ryerson university is implemented in the current investigation in order to determine the target reliability index for the serviceability limit state. This model was used previously (Morsy et al.2016) to find the reliability index using First Order Monte Carlo Simulation and will be further used in this investigation to determine the reliability index using Second Order Monte Carlo Simulation. This model presents a simplified equation that was developed for the estimation of crack spacing using neural network. The network was applied to experimental data for different kinds of structural elements such as 
oneway slab, beams, tension slabs, and two-way slabs. The proposed equation is shown to have a potential in estimations of crack spacing. The most significant parameters that are taking place for crack spacing estimation, are included in the equation, such as rebar diameter, rebar spacing and concrete cover. The equation for obtaining crack spacing estimates is presented as;

$S_{\text {avg }}=1.90 d_{b}^{0.062} S_{b^{0.514}} C_{c} c^{0.323}$

where, $\mathrm{d}_{\mathrm{b}}$ is the bar diameter; $\mathrm{S}_{\mathrm{b}}$ is the crack spacing and $\mathrm{C}_{\mathrm{c}}$ is concrete cover.

The average crack width could be calculated from the estimated crack spacing multiplied by the mean steel strain, $\varepsilon_{s}$, at the concrete surface after calculating the neutral axis. The crack spacing is determined at a steel stress of $2 / 3$ of $\mathrm{f}_{\mathrm{y}}$. Assuming that the Young's Modulus of steel is $200 \times 10^{3}$ $\mathrm{MPa}$, the mean steel stain was calculated to be 0.0012 . The equation for the average crack width is presented as;

$W_{\text {avg }}=\varepsilon_{s} S_{\text {avg }}$

The maximum crack width, $\mathrm{W}_{\max }$ is given as follows;

$W_{\max }=1.70 W_{\text {avg }}$

\subsubsection{Investigated Data}

The current investigation includes the data of sixty different beams, that includes the average crack spacing collected from various experimental studies (Frosch et al. 2003; Gilbert and Nejadi 2004; Dawood and Marzouk 2010; Rizk and Marzouk 2010; Marzouk et al. 2010) as given in Appendix A. The data includes different specimens, beams and slabs, with varying concrete strength, concrete cover, reinforcing diameter and reinforcing bar spacing. Table 1 shows 10 summarised beam design cases according to CSA Standard A23.3-04 (2014), for the reliability index study. 
Table 1: Beams cases for reliability index study

\begin{tabular}{|c|c|c|}
\hline $\begin{array}{r}\text { Bar diameter; } d \mathbf{b} \\
(\mathbf{m m})\end{array}$ & Bar spacing; $\mathrm{S}_{\mathbf{b}}(\mathrm{mm})$ & $\begin{array}{r}\text { Concrete Cover; } \mathbf{C}_{\mathbf{c}} \\
(\mathbf{m m})\end{array}$ \\
\hline 10 & 200 & 25 \\
\hline 10 & 375 & 40 \\
\hline 12 & 150 & 25 \\
\hline 12 & 308 & 25 \\
\hline 15 & 150 & 40 \\
\hline 15 & 368 & 70 \\
\hline 20 & 150 & 40 \\
\hline 20 & 300 & 50 \\
\hline 25 & 150 & 30 \\
\hline 25 & 300 & 70 \\
\hline
\end{tabular}

Table 2 shows the statistical parameters and the distribution type for the design variables mentioned above (bar diameter, bar spacing and concrete cover). The statistical parameters were obtained using Probability Paper Plot (PPP) Method as explained in Section 3.2.5. These statistical parameters were used for the MATLAB Code provided in Appendix B.

Table 2: Statistical parameters for the decision variables

\begin{tabular}{|c|c|c|c|}
\hline Design variable & Bias & Covariance & Distribution \\
\hline Bar diameter $\left(d_{b}\right)$ & 1 & 0.0175 & Normal \\
\hline Bar spacing $\left(\mathrm{S}_{\mathrm{b}}\right)$ & 1 & 0.005 & Normal \\
\hline $\begin{array}{r}\text { Concrete Cover } \\
\left(\mathrm{C}_{\mathrm{c}}\right)\end{array}$ & 0.95 & 0.1 & Normal \\
\hline
\end{tabular}

\subsubsection{Model Uncertainty}

The distribution type, mean and variance of model uncertainty $\mathrm{C}$ in equation (3.7) was fitted with observed crack spacing data, reported in Appendix A, by comparing experimental values of the crack width of experiments $\left(\mathrm{W}_{\exp }\right)$ with the corresponding analytical values, $\left(\mathrm{W}_{\max }\right)$ derived using the (Elshafey et al., 2013) model, presented in equation (3.11). The model uncertainty factor was estimated based on following formulation; 
$C=W_{\exp } / W_{\max }$

The statistical distribution parameters of the model uncertainty (C) were determined in previous research work by (Morsy et al. 2016) for calculating the reliability index for the crack width. Probability Paper Plot (PPP) method was used to identify the distribution type, mean and variance of the model uncertainty. It was fitted with observed crack width for the whole data by comparing experimental values of the crack. The mean value of $\mathrm{C}$ was obtained to be 0.995 and the standard deviation to be 0.249 fitted using lognormal distribution. In previous research work for obtaining the reliability index using the First Order Monte Carlo Simulation, C was calculated as a deterministic value however, in this study, $\mathrm{C}$ was modelled as a random variable with lognormal distribution. Modelling $\mathrm{C}$ as a random variable provides more accuracy in the reliability index value obtained.

\subsubsection{Second Order Monte Carlo Simulation}

As mentioned earlier, First Order Monte Carlo Simulation was utilized to obtain the reliability index for the 10 cases of beam design shown in Section 2.3.4. Second Order Monte Carlo Simulation was performed to obtain more accurate results of the reliability index. The results of the reliability index obtained from previous research work will be provided in Section 4.2.1 and the values will be compared with the ones obtained in this study. In order to successfully run the Second Order Monte Carlo Simulation using MATLAB (m.file), several steps were followed as shown in Figure 4; First, the crack width limit was defined to be $0.4 \mathrm{~mm}$ because the exposure will be exterior, as per the (CSA A23.3-M94, 2014). Then, the statistical parameters (mean and standard deviation) of the model uncertainty were input; these statistical parameters were then used to calculate the parameters (lambda $\lambda$ and zeta $\zeta$ ) for the lognormal distribution. Then, the initial value of each decision variable, shown in Table 1 was entered. Also, the statistical parameters of each decision variable, shown in Table 2 were input and modelled as normal distributions. Afterwards, the number of simulations were defined as 100,000 . Then, each decision variable was defined as random variable with the 
statistical parameters mentioned earlier and the corresponding distribution. Then, the performance function was defined; equation (3.7), where $\mathrm{W}_{\exp }$ was set as $0.4 \mathrm{~mm}$, as well as the equation for the probability of failure. Finally, the reliability index, $\beta$, was modelled as a function of the probability of failure as discussed in Section 3.2.2. The MATLAB Code is shown in Appendix B.
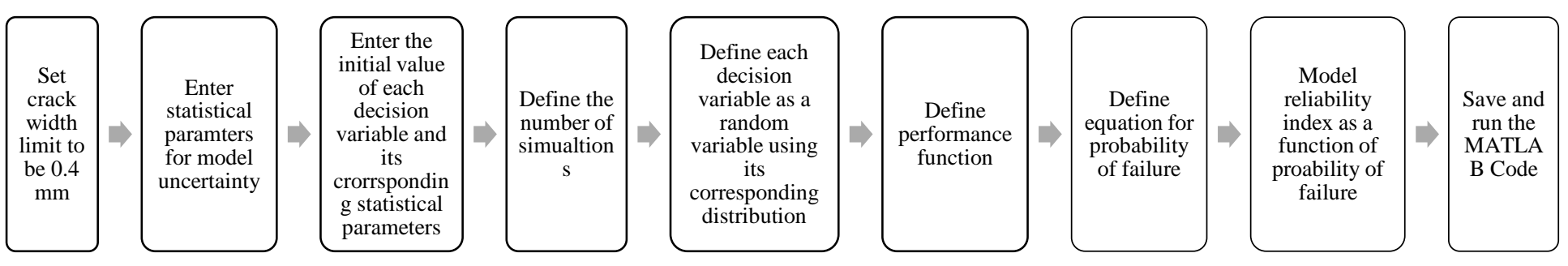

Figure 4: Steps used for Second Order Monte Carlo Simulation

\subsection{Ultimate Limit State Monitoring using Decrement Damping Performance Limits}

Recently, there are new approaches that have been proposed to be used for integrity assessment of structures; a new approach was proposed by (Modares and Venkitaraman, 2015) for structure performance assessment using a sensing-based measurement and estimation of its expected remaining lifetime using Miner's damage rule for fatigue analysis. Another approach was proposed to evaluate the bridge performance based on measured strain data (He et al., 2011). These research works mentioned that for most structural members, the acceptable limit of reliability index is equal to 3.5. Indicative values of probability of failure $\left(\mathrm{P}_{\mathrm{f}}\right)$ and corresponding reliability index for typical failure modes are presented in Table 3 as reported by (BS-EN 2012). The recommended type of failure is the SLS with large elastic deformation as it gives warning before the actual failure of the member, with reliability index range of 2.326:3.019. 
Table 3: Probability of failure and corresponding reliability index value

\begin{tabular}{|c|c|c|}
\hline Failure Type & $\begin{array}{c}\text { Probability of Failure } \\
\left(\mathbf{P}_{\mathbf{f}}\right)\end{array}$ & Reliability Index $(\boldsymbol{\beta})$ \\
\hline $\begin{array}{c}\text { ULS with no warning (brittle } \\
\text { failure) }\end{array}$ & $10_{-5: 10_{-7}}$ & $4.265: 5.199$ \\
\hline $\begin{array}{c}\text { ULS with warning (ductile } \\
\text { failure) }\end{array}$ & $10_{-4: 10_{-5}}$ & $3.719: 4.265$ \\
\hline $\begin{array}{c}\text { SLS with large elastic } \\
\text { deformation }\end{array}$ & $10_{-2: 10_{-3}}$ & $2.326: 3.019$ \\
\hline
\end{tabular}

ULS - Ultimate Limit State $\quad$ SLS - Serviceability Limit State

$\mathrm{RD}$ diagnostic approach is applied to identify the extent of damage in addition to an adequate condition assessment limits based on DD ratio for concrete beams performance evaluations to ensure a secure safety level. To estimate the structure's condition through detecting damage existence in terms of changes in the dynamic parameters of the structure, the DD ratio was used in this study to indicate the severity of the damage as its values significantly varied according to the degree of damage based on an experimental investigation. A reliability study was applied on the DD values for developing a performance assessment for the structure, thus assisting in decision-making for maintenance, repair and rehabilitation systems.

\subsubsection{Decrement Damping Performance Limits}

In the current study, a performance ranking is proposed to distinguish the current condition of the monitored structure. The proposed performance limit is based on the significant increase in DD values recorded from the laboratory investigation for the reinforced concrete beams, in addition to the results of the numerical modeling. The change in DD value can be used as a warning limit leading to giving a time to perform rehabilitation before any catastrophic disaster.

A performance ranking is performed to distinguish the condition of the monitored structure, proposed performance limits based on the data of the experimental investigation, as shown in Table

4. This rating indicates the structure's performance with the 3 limits; the first limit is safe performance of the structure at reliability index greater than or equal to 3.50 that does not require any maintenance. Thus, the low- risk limit at values $2.5-3.5$ indicates a need for a maintenance plan; 
finally, the high-risk limit that requires immediate repair or replacement for the deteriorated element of the structure to prevent any catastrophic failure. More reliability-based decision-making tables will be provided in Section 4.3.

Table 4: Decrement damping ratio reliability index for different performance limits

\begin{tabular}{|c|c|}
\hline Performance Limits & $\begin{array}{c}\text { Reliability Index for the Decrement Damping } \\
\text { Ratio }\end{array}$ \\
\hline SAFE & 3.50 \\
\hline LOW RISK & 2.50 \\
\hline HIGH RISK & 1.20 \\
\hline
\end{tabular}

Figure 5 shows a reliability index curve for the DD values, proposed limits for the performance risk limit of the structure during its service life. These limits are based on cracking, yielding and ultimate limits of the beam. The first cracking limit is considered to be in the safe zone of the structure, the yielding limit is set to be the maintenance required, and then finally the warning limit according to the laboratory investigation is proposed to be at reliability index equal to 1.20 , which is between the yield and ultimate limits of the beams.

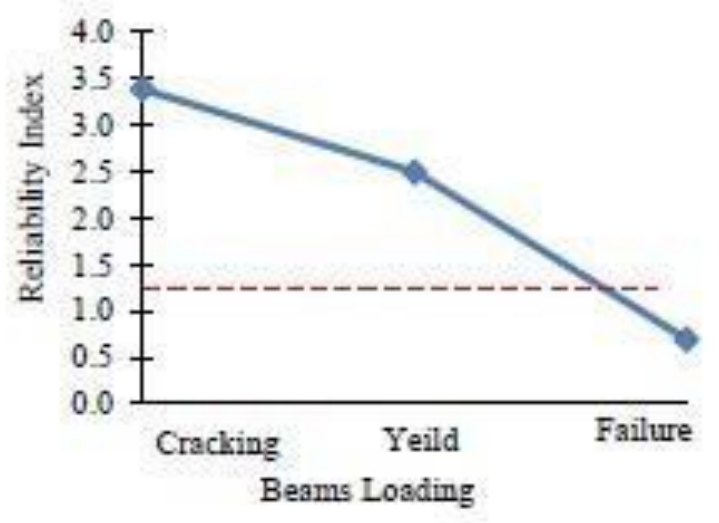

Figure 5: Proposed reliability index for the decrement damping values 


\section{CHAPTER FOUR: RESULTS OBTAINED FROM SIMULATION}

\subsection{Introduction}

This chapter presents the results obtained from the reliability index calibration methodology explained in Chapter 3. The probability of failure and reliability index values as well as the maximum crack width value obtained for the 10 beam design cases will be shown and the analysis of the results will be explained. Also, a comparison between the findings of previous research work (First Order Monte Carlo Simulation) and the current study (Second Order Monte Carlo Simulation) will be presented. The current study findings include graphs that indicate how the reliability index is affected by different decision parameters and how the maximum crack width is related to the reliability index. Finally, several steps for the decision-making process using the results obtained will be discussed.

\subsection{Results Obtained from Second Order Monte Carlo Simulation}

After running the Second Order Monte Carlo Simulation as described in Section 3.2.6 for all the 10 beam design cases, the following values for the maximum crack width, probability of failure and reliability index were obtained, as shown in Table 5.

Table 5: Results of reliability index for all studied cases

\begin{tabular}{|c|c|c|c|c|c|}
\hline $\begin{array}{l}\text { Bar } \\
\text { Diameter; } \\
\mathbf{d}_{\mathbf{b}}(\mathbf{m m})\end{array}$ & $\begin{array}{l}\text { Bar } \\
\text { Spacing; } \\
\mathbf{S}_{\mathbf{b}}(\mathbf{m m})\end{array}$ & $\begin{array}{l}\text { Concrete } \\
\text { Cover; } \\
\mathbf{C}_{\mathbf{c}}(\mathbf{m m})\end{array}$ & $\begin{array}{l}\text { Probability of } \\
\text { Failure; } \mathbf{P}_{\mathbf{f}}\end{array}$ & $\begin{array}{l}\text { Max Crack } \\
\text { Width (mm) }\end{array}$ & $\begin{array}{l}\text { Reliability } \\
\text { Index; } \boldsymbol{\beta}\end{array}$ \\
\hline 10 & 200 & 25 & $9.14 \times 10^{-4}$ & 0.1914 & 3.12 \\
\hline 10 & 375 & 40 & $1.15 \times 10^{-3}$ & 0.3077 & 2.29 \\
\hline 12 & 150 & 25 & $1.23 \times 10^{-4}$ & 0.1669 & 3.67 \\
\hline 12 & 308 & 25 & $1.10 \times 10^{-3}$ & 0.2416 & 2.38 \\
\hline 15 & 150 & 40 & $1.30 \times 10^{-3}$ & 0.1970 & 3.00 \\
\hline 15 & 368 & 70 & $1.13 \times 10^{-3}$ & 0.3744 & 2.31 \\
\hline 20 & 150 & 40 & $1.80 \times 10^{-3}$ & 0.2005 & 2.92 \\
\hline 20 & 300 & 50 & $1.20 \times 10^{-3}$ & 0.3078 & 2.40 \\
\hline 25 & 150 & 30 & $5.65 \times 10^{-4}$ & 0.1853 & 3.26 \\
\hline 25 & 300 & 70 & $1.12 \times 10^{-3}$ & 0.3479 & 2.35 \\
\hline
\end{tabular}




\subsubsection{Interpretation of Results}

As seen in Table 5, the reliability index values are between 2.29 and 3.67 which is close to the recommended SLS range, which is between 2.326 and 3.019. In addition, all the crack width values obtained are less than $0.4 \mathrm{~mm}$, which is the maximum crack width limit for exterior exposure. Therefore, it can be concluded that the adapted crack width model is acceptable and can be used to estimate the crack spacing and crack width of reinforced concrete members.

In order to utilise the reliability index values obtained, a relationship between the maximum crack width and bar spacing and the reliability index can be determined. Figure 6 shows the relationship between the maximum crack width and the reliability index.

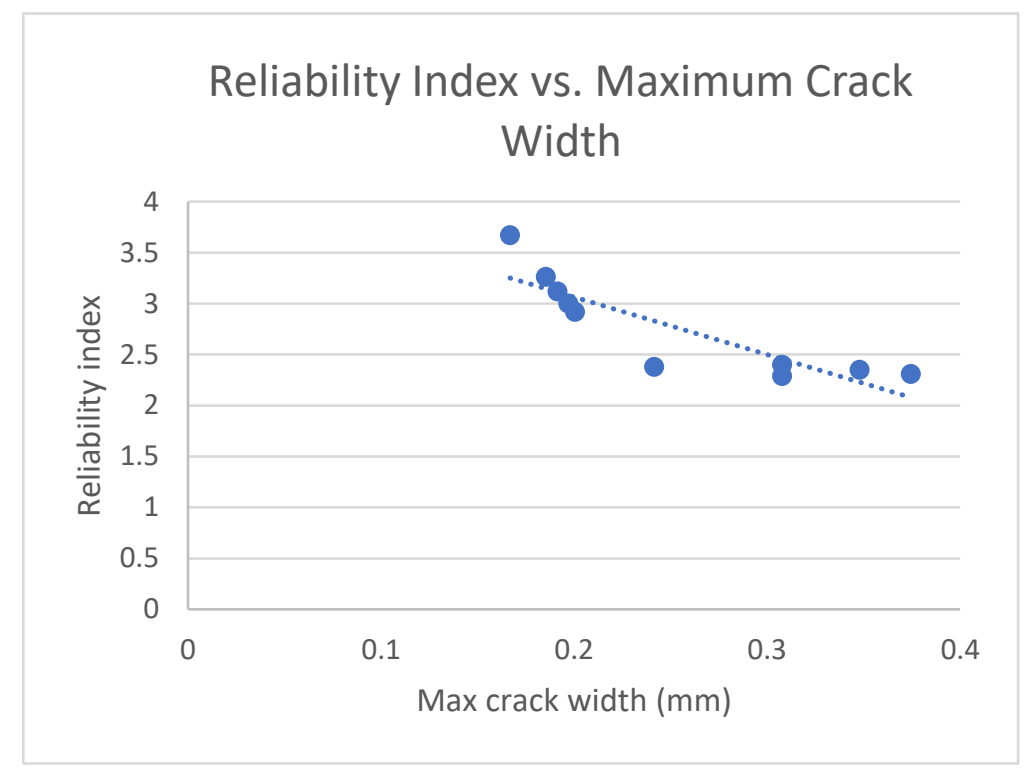

Figure 6: Reliability index vs. maximum crack width

As seen in Figure 6, the reliability index decreases as the crack width increases because an increase in the crack width indicates that the tensile stresses are propagating more inside the concrete structure hence, the concrete will be more susceptible to damage/corrosion and deteriorate at a faster rate. As a result, the reliability of the structure will decrease. 
Figure 7 shows the relationship between the bar spacing and the reliability index.

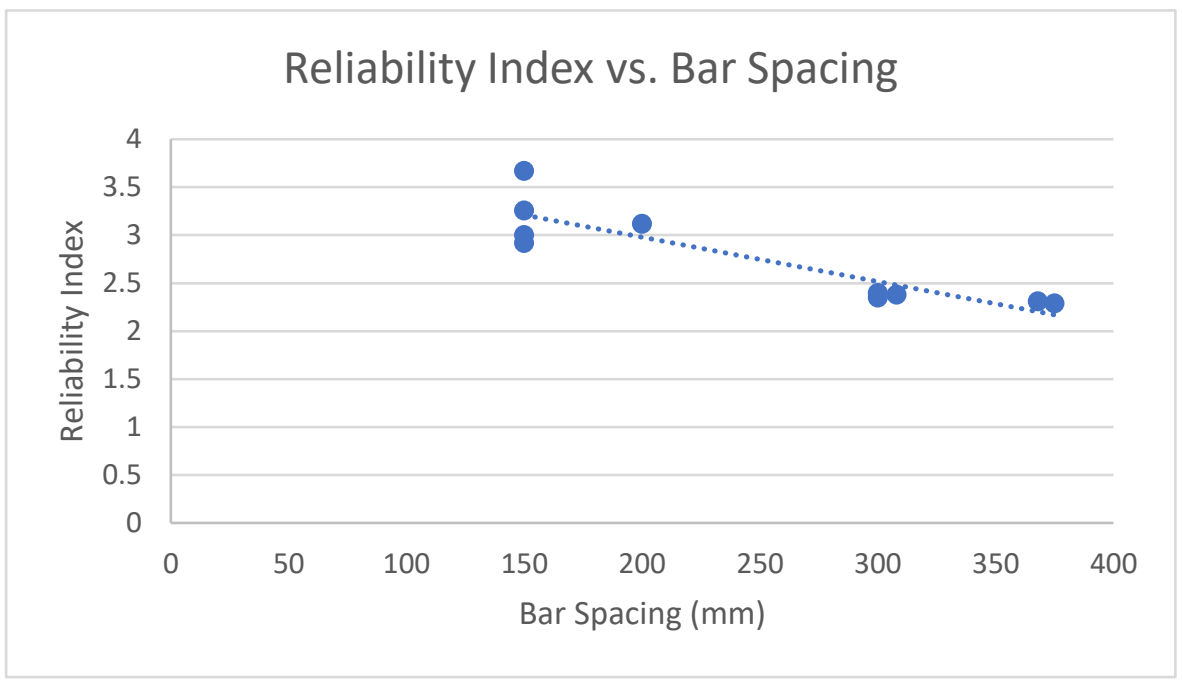

Figure 7: Reliability index vs. bar spacing

As seen in Figure 7, the reliability index decreases as the reinforcement bar spacing increases. As bar spacing increases, the ability of the concrete structure to tolerate tensile stresses decreases because the steel reinforcement carries the tensile stresses, this will weaken the concrete structure and hence the structure's reliability index will decrease.

The bar spacing parameter is the controlling parameter in equation (3.9) because it has the highest power (0.514). This means that, any change in the bar spacing will greatly impact the average crack spacing and hence the maximum crack width. This significance can be seen from the results obtained in Second Order Monte Carlo Simulation, rather than the First Order Monte Carlo Simulation, which indicates that Second Order Monte Carlo Simulation gives more accurate and reliable results. Using the results in Table 5 and the interpretation above, it can be concluded that the optimum values for bar spacing and concrete cover is between $150 \mathrm{~mm}$ and $200 \mathrm{~mm}$, and $25 \mathrm{~mm}$ and $30 \mathrm{~mm}$; respectively.

The results and analysis of the tested crack width model and adapted method of Second Order Monte Carlo Simulation are reasonable; therefore, it is safe to say that the tested crack width model and methodology can be used to successfully determine the reliability index of a structure and hence make a decision based on statistical parameters and data rather than subjective rating. 


\subsubsection{Comparison Between Results from Previous Research Work and Current Findings}

Table 6 shows the results obtained from previous research work (Morsy et al. 2016) which included determining the reliability index using First Order Monte Carlo Simulation.

Table 6: Reliability index values of previous research work

\begin{tabular}{|c|c|c|c|c|}
\hline $\begin{array}{l}\text { Bar Diameter; } \\
\mathbf{d}_{\mathbf{b}}(\mathbf{m m})\end{array}$ & $\begin{array}{l}\text { Bar Spacing; } \\
\mathbf{S}_{\mathbf{b}}(\mathbf{m m})\end{array}$ & $\begin{array}{l}\text { Concrete Cover; } \\
\mathbf{C}_{\mathbf{c}}(\mathbf{m m})\end{array}$ & $\begin{array}{l}\text { Probability of } \\
\text { Failure; } \mathbf{P}\end{array}$ & $\begin{array}{l}\text { Reliability } \\
\text { Index; } \boldsymbol{\beta}\end{array}$ \\
\hline 10 & 200 & 25 & $3.90 \times 10^{-4}$ & 3.01 \\
\hline 10 & 375 & 40 & $4.26 \times 10^{-4}$ & 3.15 \\
\hline 12 & 150 & 25 & $1.70 \times 10^{-4}$ & 2.92 \\
\hline 12 & 308 & 25 & $2.70 \times 10^{-4}$ & 2.78 \\
\hline 15 & 150 & 40 & $3.20 \times 10^{-4}$ & 3.02 \\
\hline 15 & 368 & 70 & $3.11 \times 10^{-4}$ & 2.38 \\
\hline 20 & 150 & 40 & $3.67 \times 10^{-4}$ & 2.97 \\
\hline 20 & 300 & 50 & $3.07 \times 10^{-4}$ & 3.03 \\
\hline 25 & 150 & 30 & $2.87 \times 10^{-4}$ & 2.85 \\
\hline 25 & 300 & 70 & $3.14 \times 10^{-4}$ & 3.02 \\
\hline
\end{tabular}

As shown in Table 6, the results of previous research work and current findings are similar. The reliability index values range is 2.38:3.15 which is close to the recommended range of 2.30:3.019 to satisfy the SLS performance limits. This indicates that the tested maximum crack width model and adapted simulation methodology is reliable and can be used to determine the reliability index of reinforced concrete members. However, Second Order Monte Carlo Simulation can be considered more accurate because it reflects the effect of increasing reinforcement bar spacing $\left(\mathrm{S}_{\mathrm{b}}\right)$ on the reliability index more than that in First Order Monte Carlo Simulation. Table 7 illustrates the comparison between previous and current research work. 
Table 7: Comparison between previous and current research work

\begin{tabular}{|c|l|l|}
\hline $\begin{array}{c}\text { Comparison } \\
\text { Criteria }\end{array}$ & \multicolumn{1}{|c|}{$\begin{array}{c}\text { First Order Monte Carlo } \\
\text { Simulation }\end{array}$} & \multicolumn{1}{c|}{$\begin{array}{c}\text { Second Order Monte Carlo } \\
\text { Simulation }\end{array}$} \\
\hline $\begin{array}{c}\text { Reliability } \\
\text { index values } \\
\text { obtained }\end{array}$ & $\begin{array}{l}\text { The reliability index values } \\
\text { obtained were within the } \\
\text { recommended range of } \\
2.30: 3.019\end{array}$ & $\begin{array}{l}\text { The reliability index values obtained } \\
\text { were within the recommended range of } \\
2.30: 3.019\end{array}$ \\
\hline $\begin{array}{c}\text { Probability of } \\
\text { failure values } \\
\text { obtained }\end{array}$ & $\begin{array}{l}\text { The probability of failure values } \\
\text { obtained didn't reflect a clear } \\
\text { conclusion about the variation of } \\
\text { the values of the decision } \\
\text { variables. }\end{array}$ & $\begin{array}{l}\text { The probability of failure values } \\
\text { obtained were more reflective of the } \\
\text { variation of values of the decision } \\
\text { variables. }\end{array}$ \\
\hline Accuracy & $\begin{array}{l}\text { The effect of increasing } \\
\text { reinforcement bar spacing }\left(\mathrm{S}_{\mathrm{b}}\right) \\
\text { was not clearly reflected on the } \\
\text { reliability index values obtained }\end{array}$ & $\begin{array}{l}\text { The effect of increasing reinforcement } \\
\text { bar spacing (S) was clearly reflected on } \\
\text { the reliability index values obtained. } \\
\text { Therefore, the results obtained can be } \\
\text { considered more accurate than the ones } \\
\text { obtained in First Order Monte Carlo } \\
\text { Simulation. }\end{array}$ \\
\hline
\end{tabular}

\subsection{Decision-Making using the Results Obtained}

Decision-making based on the reliability index data obtained can be achieved by comparing the value of reliability index obtained with the performance limits in Table 4. A performance ranking is developed to distinguish the condition of the monitored structure using the proposed performance limits, which indicates the structure's performance by the three limits, shown in Figure 4. These limits are based on cracking, yielding and ultimate limits of the beam. The first cracking limit is considered to be in the safe zone of the structure, the yielding limit is set to be maintenance required, and then finally the warning limit according to the laboratory and numerical investigations is proposed to be between the yield and ultimate limits of the beams. A diagnostic approach is introduced, as shown in Figure 8, to achieve an efficient health monitoring strategy for the concrete structures. 


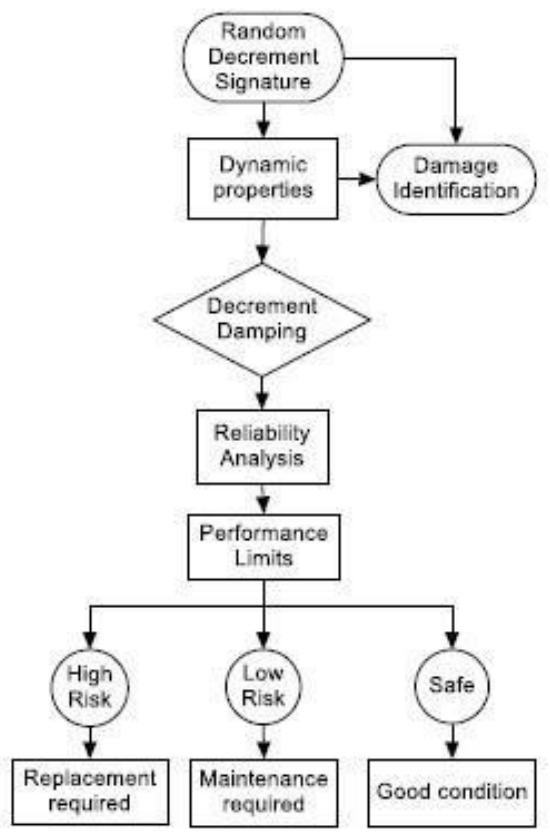

Figure 8: Diagnostic approach for performance limits of concrete structures

A performance ranking is performed to distinguish the condition of the monitored structure, proposed performance limits based on the data of the experimental investigation, as shown in Table

4. This rating indicates the structure's performance with the 3 limits; the first limit is safe performance of the structure at reliability index greater than or equal to 3.50 that does not require any maintenance. Thus, the low risk limit at values 2.5-3.5 indicates a need for a maintenance plan. Finally, the high-risk limit that requires immediate repair or replacement for the deteriorated element of the structure to prevent any catastrophic failure. (Concrete Preservation Alliance, 2018) Therefore, the following steps can be adapted to guide the decision-maker when evaluating the structural health of a reinforced concrete member, (American Concrete Institute Commitee, 2009)

1) Collect the structural parameters of the reinforced concrete member (bar diameter, bar spacing, concrete cover etc).

2) Run Second Order Monte Carlo Simulation as described in Section 3.2.6.

3) Determine the reliability index value.

4) Use Figure 8 and Table 4 to determine the structural health of the tested concrete member. 
5) Determine the maximum crack width value.

6) If the obtained crack width value is less than $0.4 \mathrm{~mm}$ then, the member is considered acceptable however, the following table can be used to determine the appropriate action to be taken,

Table 8: Suggested action depending on the crack width

\begin{tabular}{|c|c|}
\hline Crack Width & Suggested Action \\
\hline Between $0.05 \mathrm{~mm}$ and $0.3 \mathrm{~mm}$ & Use low viscosity epoxy injection \\
\hline Between $0.3 \mathrm{~mm}$ and $2 \mathrm{~mm}$ & $\begin{array}{l}\text { For vertical cracks: the epoxy is injected using } \\
\text { ports, two at a minimum spaced at eight inches } \\
\text { along the concrete crack. Start by injecting at the } \\
\text { lowest port and keep applying until the epoxy is } \\
\text { coming out of the next port or when the epoxy is } \\
\text { no longer flowing. } \\
\text { For horizontal cracks: start at the widest point of the } \\
\text { crack to inject the epoxy. }\end{array}$ \\
\hline
\end{tabular}




\section{CHAPTER FIVE: SUMMARY AND CONCLUSIONS}

Structural Health Monitoring (SHM) occurs periodically to identify the damage level and the structure performance. This step is crucial in decision making process; a decision of whether to fix the bridge (resurfacing), rehabilitate it or demolish it depends on the structural performance data obtained during the SHM process. Most structural defects are related to serviceability conditions rather than strength. One of the main serviceability conditions of concrete is the crack width. The crack width is usually controlled by the cracking limit state. The serviceability limit state (SLS) provides a maximum crack width limit. If the structure's crack width exceeds the limit, a decision has to be taken, whether to inject the crack or resurface the structure. The reliability index of crack limit can be investigated using Monte Carlo Simulation. In this study, Second Order Monte Carlo Simulation was performed to determine the reliability index of a reinforced concrete $(\mathrm{RC})$ member/structure. The data of ten beam design cases were used to determine the reliability index and to assess the serviceability limit state using a statistical method. A proposed crack width model was used to determine the crack width using several structure parameters (bar diameter, bar spacing and concrete cover). The parameters were randomly distributed on MATLAB, where the simulation was run 100,000 times to determine the reliability index for each design case. The reliability index of all the design cases was within the SLS range. A decision-making technique was developed to guide the decision-maker through the decision-making process.

Based on the results of the investigation, the following conclusions are drawn,

1. The reliability indexes developed for the serviceability limit state that is based on sixty crack spacing data points that were summarised as ten beam design cases obtained from previous research works; to distinguish the validity of any proposed equation for predicting the crack width to be used for monitoring concrete structure at the 
serviceability limit state. Second Order Monte Carlo simulation was used to calculate the probability of failure and the reliability index. The reliability indexes values were close to the values recommended by the code indicating that the examined equation showed a very good potential for estimating crack width for reinforced concrete members. In addition, this could be implemented in the proposed monitoring strategy at the serviceability limit state as a target limit for monitoring the maximum crack width.

2. After comparing the results obtained in the current investigation with previous research work that was performed using First Order Monte Carlo Simulation, it can be concluded that Second Order Monte Carlo Simulation provides more accurate results since, it reflects the controlling parameters in the proposed crack width equation. However, the results obtained from the previous research work is very close to the ones obtained in this study. This proves that the proposed methodology for calibrating the reliability index for RC members is valid and can be used.

3. A decision-making procedure was developed using the obtained results to help in the decision-making process. This means that, the decision-making process can be carried out based on statistical parameters/values rather than a subjective number/opinion. The decision to inject or seal the crack can be carried out based on the crack width data for a specific RC member as outlined earlier.

4. The study indicates that the probabilistic methods enable the calibration and development of new theoretical models that can be applied in the design codes to enhance the safety of the structures. The reliability analysis and mathematical statistics indicate that it can be used for the analysis of the reliability of the structures and assessment of theoretical models. 


\section{APPENDIX A}

The table below shows the 60 sets of data that were used in previous research work, obtained from (Frosch et al. 2003; Gilbert and Nejadi 2004; Dawood and Marzouk 2010; Rizk and Marzouk 2010; Marzouk et al. 2010). and where the 10 beam design cases were generated from.

\begin{tabular}{|c|c|c|c|c|c|c|c|}
\hline Reference & Beam & $\begin{array}{c}f_{a u^{\prime}} \\
\text { (Mpa) }\end{array}$ & $\begin{array}{c}\text { Bar Diameter } \\
(\mathrm{mm})\end{array}$ & $\begin{array}{l}\text { Bar Spacing } \\
\text { (mm) }\end{array}$ & $\begin{array}{c}\text { Concrete } \\
\text { Cover }(\mathrm{mm})\end{array}$ & $\rho \%$ & $\begin{array}{c}\text { Crack } \\
\text { spacing } \\
(\mathrm{mm})\end{array}$ \\
\hline \multirow{11}{*}{$\begin{array}{l}\text { Gilbert } \\
\text { and } \\
\text { Nejadi, } \\
2004\end{array}$} & B1-b & 36 & 16 & 150 & 40 & 1.15 & 192 \\
\hline & B2-a & 36 & 16 & 180 & 25 & 1.20 & 149 \\
\hline & B2-b & 36 & 16 & 180 & 25 & 1.20 & 163 \\
\hline & B3-a & 36 & 16 & 90 & 25 & 1.80 & 109 \\
\hline & B3-b & 36 & 16 & 90 & 25 & 1.80 & 104 \\
\hline & S1-a & 36 & 12 & 308 & 25 & 1.40 & 131 \\
\hline & S1-b & 36 & 12 & 308 & 25 & 1.40 & 128 \\
\hline & S2-a & 36 & 12 & 154 & 25 & 2.11 & 92 \\
\hline & S2-b & 36 & 12 & 154 & 25 & 2.11 & 131 \\
\hline & S3-a & 36 & 12 & 103 & 25 & 2.81 & 89 \\
\hline & S3-b & 36 & 12 & 103 & 25 & 2.81 & 117 \\
\hline \multirow{10}{*}{$\begin{array}{c}\text { Frosh and } \\
\text { Blackman, } \\
2003\end{array}$} & B-6 & 47 & 16 & 152 & 38 & 5.91 & 175 \\
\hline & B-9 & 44 & 16 & 229 & 38 & 3.94 & 229 \\
\hline & B-12 & 44 & 16 & 305 & 38 & 2.96 & 249 \\
\hline & B-18 & 47 & 16 & 457 & 38 & 1.97 & 310 \\
\hline & E12-6 & 47 & 16 & 152 & 38 & 5.91 & 170 \\
\hline & E12-9 & 46 & 16 & 229 & 38 & 3.94 & 226 \\
\hline & E12-12 & 46 & 16 & 305 & 38 & 2.96 & 257 \\
\hline & E12-18 & 47 & 16 & 457 & 38 & 1.97 & 338 \\
\hline & E6-9 & 46 & 16 & 229 & 38 & 3.94 & 203 \\
\hline & E18-9 & 46 & 16 & 229 & 38 & 3.94 & 188 \\
\hline \multirow{13}{*}{$\begin{array}{c}\text { Dawood } \\
\text { and } \\
\text { Marzouk, } \\
2011\end{array}$} & NS-U-15-2.5 & 40 & 15 & 150 & 37.5 & 1.2 & 151 \\
\hline & NS-B1-15-2.5 & 35 & 15 & 150 & 37.5 & 1.2 & 144 \\
\hline & HS-U-15-2.5 & 90 & 15 & 150 & 37.5 & 1.2 & 152 \\
\hline & HS-B1-15-2.5 & 75 & 15 & 150 & 37.5 & 1.2 & 151 \\
\hline & HS-U-20-2.5 & 75 & 20 & 150 & 50 & 2 & 150 \\
\hline & HS-B1-20-2.5 & 75 & 20 & 150 & 50 & 2 & 148 \\
\hline & HS-U-20-2.5 & 80 & 20 & 300 & 50 & 1.2 & 240 \\
\hline & HS-B1-20-2.5 & 75 & 20 & 300 & 50 & 1.2 & 275 \\
\hline & HS-U-25-2.5 & 75 & 25 & 300 & 62.5 & 1.2 & 270 \\
\hline & HS-B1-25-2.5 & 65 & 25 & 300 & 62.5 & 1.2 & 290 \\
\hline & HS-U-25-1.5 & 75 & 25 & 300 & 37.5 & 1.2 & 240 \\
\hline & HS-B1-25-1.5 & 70 & 25 & 300 & 37.5 & 1.2 & 285 \\
\hline & HS-B2-25-2.5 & 60 & 25 & 300 & 62.5 & 1.2 & 290 \\
\hline
\end{tabular}




\begin{tabular}{|c|c|c|c|c|c|c|c|}
\hline & HS-B3-25-2.5 & 65 & 25 & 300 & 62.5 & 1.2 & 305 \\
\hline & HS-B4-25-2.5 & 65 & 25 & 300 & 62.5 & 1.2 & 230 \\
\hline & HS-U-30-2.5 & 65 & 30 & 300 & 75 & 1.2 & 290 \\
\hline & HS-B1-30-2.5 & 65 & 30 & 300 & 75 & 1.2 & 295 \\
\hline & HS-U-30-1.5 & 65 & 30 & 300 & 75 & 1.2 & 300 \\
\hline \multirow{8}{*}{$\begin{array}{c}\text { Rizk and } \\
\text { Marzouk, } \\
2010\end{array}$} & NS1 & 44.7 & 10 & 210 & 45 & 1.50 & 201 \\
\hline & NS2 & 50.2 & 15 & 240 & 40 & 2 & 221 \\
\hline & NS3 & 35 & 15 & 368 & 60 & 2.5 & 245 \\
\hline & HS1 & 70 & 15 & 368 & 60 & 2.5 & 362 \\
\hline & NS4 & 35 & 25 & 368 & 70 & 3 & 261 \\
\hline & HS2 & 64.7 & 25 & 368 & 70 & 3 & 246 \\
\hline & HS4 & 70 & 25 & 368 & 70 & 3.5 & 264 \\
\hline & HS5 & 70 & 25 & 217 & 70 & 3.5 & 250 \\
\hline \multirow{8}{*}{$\begin{array}{c}\text { Marzouk } \\
\text { and } \\
\text { Hussein, } \\
2010\end{array}$} & $\mathrm{NSC1}$ & 35 & 25 & 150 & 30 & 2 & 134 \\
\hline & $\mathrm{HSC1}$ & 68.5 & 25 & 150 & 50 & 2 & 171 \\
\hline & $\mathrm{HSC} 2$ & 70 & 25 & 150 & 60 & 2 & 185 \\
\hline & $\mathrm{HSC} 3$ & 66.7 & 25 & 200 & 30 & 2 & 163 \\
\hline & $\mathrm{HSC} 4$ & 61.2 & 25 & 250 & 30 & 2 & 172 \\
\hline & HSC 5 & 70 & 15 & 100 & 30 & 1.5 & 120 \\
\hline & $\mathrm{NSC} 2$ & 33 & 15 & 240 & 30 & 2 & 223 \\
\hline & NSC3 & 34 & 10 & 210 & 40 & 1.5 & 239 \\
\hline
\end{tabular}




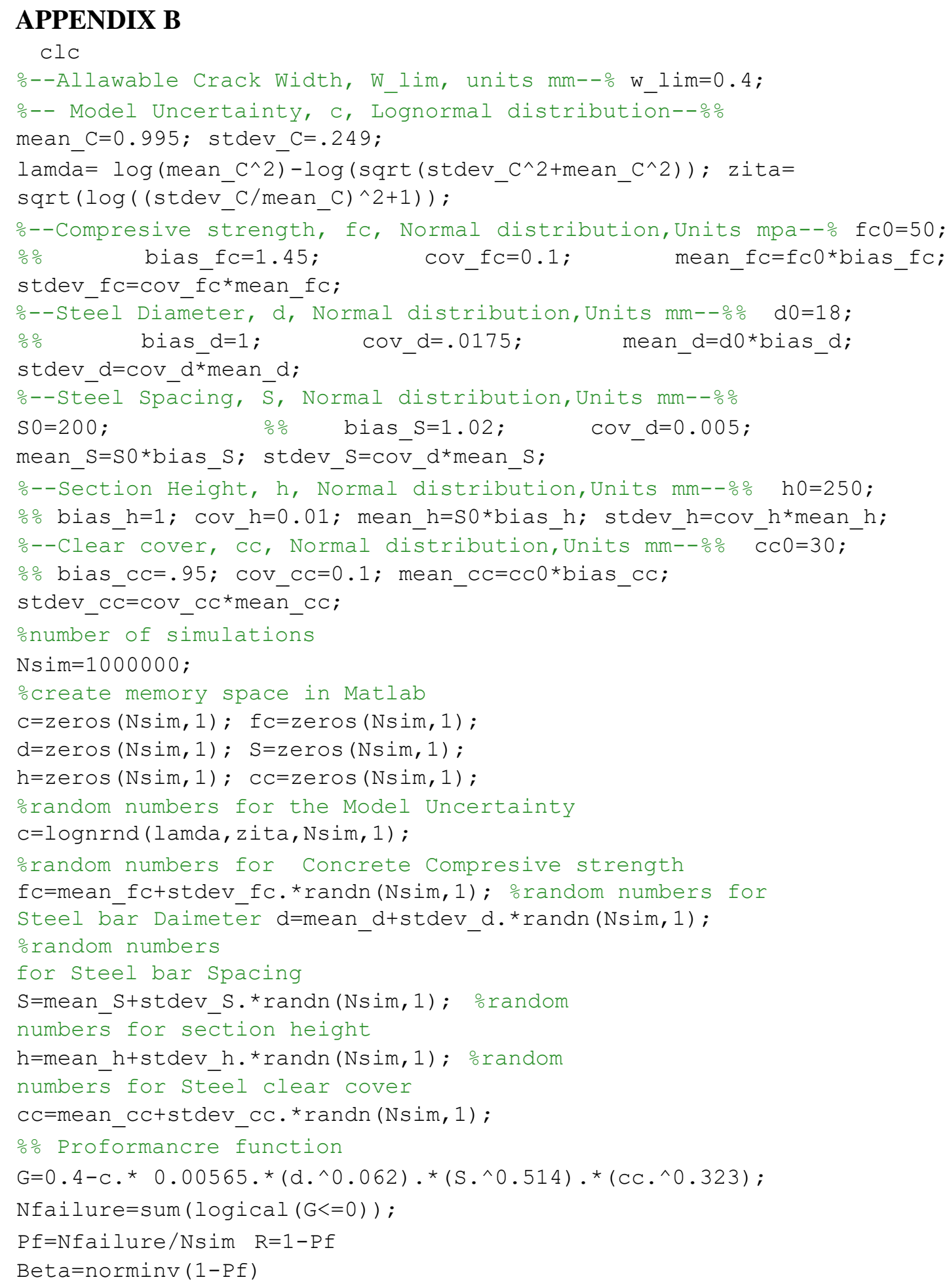




\section{REFERENCES}

American Concrete Institute Committee E706, 2009, "Structural Crack Repair by Epoxy Injection (E706.1R-09),"

BS-EN (2002). Basis of structural design British-Adopted European Standard, Eurocode.

Concrete Preservation Alliance. (2018). Concrete Repair: Epoxy Crack Injection. Retrieved from https://www.wesavestructures.info/epoxy-crack-repair

CSA Standard A23.3-14 (2014). Design of Concrete Structures. Canadian Standards Association, Canada.

Dawood N \& Marzouk H (2010). An analytical model for crack spacing of thick reinforced concrete plates. Engineering Structures, 32(2), pp.472-482.

Dawood N \& Marzouk H (2011). Crack width model for thick reinforced concrete plates subjected to in-plane forces. Canadian Journal of Civil, 38(March), pp.1262-1273.

Ellingwood, B. R. (2003). Toward load and resistance factor design for fiber-reinforced polymer composite structures. Journal of Structural Engineering, 129(4), 449-458.

Elshafey A, Dawood N, Marzouk H, \& Haddara M (2013). Predicting of crack spacing for concrete by using neural networks. Engineering Failure Analysis, 31, pp.344-359.

Frangopol, D. M., Kong, J. S., and Gharaibeh, E. S., (2001). Reliability-based life-cycle management of highway bridges. Journal of computing in civil engineering, 15(1), 27-34.

Frosch, R., Blackman, D., and Radabough, R. (2003). Investigation of Bridge Deck Cracking in Various Bridge Superstructure Systems, West Lafayette, Indiana, USA.

Giatec. (2019). Evaluating Cracking in Concrete. Retrieved from https://www.giatecscientific.com/education/cracking-in-concrete-procedures/

Gilbert, R., and Nejadi, S., (2004). An experimental study of flexural cracking in reinforced concrete members under sustained loads, University of New South, Wales, Sydeny, Australia.

He, X. H., Hua, X. G., Chen, Z. Q., and Huang, F. L. (2011) Emd-based random decrement technique for modal parameter identification of an existing railway bridge. Engineering structures, 33(4), 1348-1356. 
He, Z., and Qiu, F. (2008). Reliability assessment on maximum crack width of GFRP reinforced concrete beams. In proceeding of fourth international conference on FRP composities in civil engineering, Zurich, Switzerland. CICE2008.

Honfi, D., Mårtensson, A., and Thelandersson, S. (2012). Reliability of beams according to Eurocodes in serviceability limit state. Engineering Structures, 35, 48-54.

H.S. Müller, (2010) Non-Destructive Evaluation of Reinforced Concrete Structures: Deterioration Processes and Standard Test Methods. Woodhead Publishing Limited.

Investopedia. (2019). Monte Carlo Simulation Definition. Retrieved from https://www.investopedia.com/terms/m/montecarlosimulation.asp

Ismail, Z., Razak, H., and Rahman, A., (2006). Determination of Damage Location in RC Beams Using Mode Shape Derivatives. Engineering Structures, 28 (11), 1566-1573.

Jiang, Y., Saito, M. \& Sinha, K. C. 1988. Bridge performance prediction model using the Markov chain. Transp. Res. Rec., 25-32.

Kwon, S. J., Na, U. J., Park, S. S., and Jung, S. H. (2009). Service life prediction of concrete wharves with early-aged crack: Probabilistic approach for chloride diffusion.

Modares, M., and Venkitaraman, S. (2015) Reliable condition assessment of structures using hybrid structural measurements and structural uncertainty analyses. Structural safety, 52, 202208.

Morcous, G. (2006). Performance prediction of bridge deck systems using Markov chains. Journal of performance of Constructed Facilities, 20(2), 146-155.

Othman, H, Morsy, R. and Marzouk, H. "Calibration of Reliability Index of Reinforced Concrete for Crack Spacing” CSCE- $4^{\text {th }}$ International Structural Speciality Conference, Halifax, NS, May 2014.

Palisade. (2019). What is Monte Carlo Simulation. Retrieved from https://www.palisade.com/risk/monte_carlo_simulation.asp

Quan, Q., and Gengwei, Z. (2002). Calibration of reliability index of RC beams for serviceability limit state of maximum crack width. Reliability Engineering \& System Safety, 75(3), 359-366.

Rizk, E., and Marzouk, H. (2010). A new formula to calculate crack spacing for concrete plates. ACI structural journal, (107), 43-52. 
Robelin, C. A., and Madanat, S. M. (2007). History-dependent bridge deck maintenance and replacement optimization with Markov decision processes. Journal of Infrastructure Safety, 31(1), 75-83. Systems, 13(3), 195-201.

The American Concrete Institute, Building Code Requirements for Reinforced Concrete, ACI 318 (2016) 